\title{
PROMOÇÃO DA SAÚDE E EDUCAÇÃO INFANTIL: CAMINHOS PARA O DESENVOLVIMENTO ${ }^{1}$
}

\author{
Patrícia Carla de Souza Della Barba \\ Cláudia Maria Simões Martinez ${ }^{2}$ \\ Bianca Gonçalves Carrasco \\ Universidade Federal de São Carlos
}

\begin{abstract}
Resumo: Este estudo tem por objetivo uma reflexão acerca dos aspectos envolvidos na melhoria da qualidade de vida de crianças e suas famílias. São abordados questões e temas relativos ao cuidado e educação, do ponto de vista histórico-social, bem como situações de vulnerabilidade e pobreza. O aporte teórico utilizado está apoiado nos indicadores da UNESCO, Ministério da Saúde e publicado originalmente pela Organization for Economic Co-operation and Development. Discute-se o conceito e a efetivação das práticas de educação infantil no Brasil, destacando ações de desenvolvimento e promoção da saúde na infância, o empowerment e intersetorialidade, na perspectiva da construção de caminhos para minimizar ou atenuar os inúmeros estressores aos quais as famílias de parcelas menos favorecidas da população estão expostos; reafirma-se a necessidade do investimento na formação continuada dos educadores, considerando que resultados satisfatórios são obtidos quando a intervenção envolve a família, a comunidade e os serviços públicos.
\end{abstract}

Palavras-chave: Desenvolvimento infantil; promoção à saúde; formação de educadores; educação infantil

\section{HEALTH PROMOTION AND EARLY EDUCATION: PATHWAY OF CHILD DEVELOPMENTAL}

\begin{abstract}
The aim of this study is to promote a reflection about the aspects related to the improvement of life quality of children and their families. Items and themes related to care and education are pointed out, using the social-historical point of view, as well as aspects of vulnerability and poverty situations. The theory is based on the indicators presented by UNESCO, the Brazilian Health Agency and it was originally published by OECD (Organization for Economic Co-operation and Development). The concept and effective practices of children education in Brazil are presented, highlighting development and health-promotion actions in childhood, also empowerment and intersectionality, with the perspective of constructing ways to minimize the great amount of stressors that the families from less favored classes are exposed to. The necessity of investments for the continuous training of the educators is reaffirmed, considering that satisfactory results are obtained when the intervention involves family, community and public services.
\end{abstract}

Key-words: child development; health promotion; early education; nursery's education

\section{Educação e cuidado na primeira infância: indicadores de desenvolvimento}

O estudo publicado pela Organização para Cooperação e Desenvolvimento Econômico (OCDE UNESCO, 2002) considera que a expressão - educação e cuidado na primeira infância (ECPI) - in-

\footnotetext{
${ }^{1}$ Artigo recebido para publicação em 24/07/03; aceito em 18/10/03.

2 Endereço para correspondência: Cláudia Maria Simões Martinez, Dep. de Terapia Ocupacional, Universidade Federal de São Carlos, Rod. Washington Luiz, Km 235, São Carlos, SP, Cep 13565-905 E-mail:claudia@power.ufscar.br
}

clui todas as modalidades que garantem a educação e cuidado das crianças antes da idade da escolaridade obrigatória, independentemente da organização do espaço, do financiamento, dos horários de funcionamento ou do conteúdo do programa. Tal estudo pressupõe que "educação e cuidado" são conceitos inseparáveis, e que devem ser necessariamente levados em consideração nos serviços destinados às crianças. Entretanto, mostra que mesmo nos países participantes da OCDE há o emprego de terminologias diferentes, como "jardim de infância”, ou "educa- 
ção pré-escolar”. Na prática, observam-se abordagens incoerentes dos serviços, uma vez que, em certas estruturas ditas de "cuidado", existem possibilidades de ensino e em outras que seriam ditas educativas o que, na verdade, é oferecido é o cuidado às crianças. Nesta perspectiva, o resultado da divergência de terminologia é a desarticulação entre política e prestação de serviço ${ }^{3}$.

Como alternativa, o estudo da OCDE (2002) propõe que a expressão "educação e cuidado na primeira infância" indique uma abordagem integrada e coerente, tanto da política quanto da prestação de serviços, e que inclua a criança e seus pais, independentemente do status profissional ou socioeconômico.

Os objetivos que embasam a política de educação e cuidado na primeira infância na maioria dos países membros da OCDE são: facilitar a integração das mães das crianças no mercado de trabalho e conciliar responsabilidades profissionais e familiares; apoiar as crianças e familiares em "situação de risco" e favorecer igualdade de oportunidades de acesso à educação ao longo da vida; auxiliar na implantação de ambientes que estimulem o desenvolvimento global e o bem-estar da criança; facilitar a preparação para o ingresso na escola e manter a integração e a coesão sociais.

O estudo aponta que quando a educação na primeira infância era vista nos países membros como responsabilidade privada (dos pais e não da sociedade), as políticas públicas ocupavam-se somente das crianças em situação de risco. É, portanto, recente tanto a abordagem mais abrangente da educação e cuidado por parte do poder público para toda a população, como a própria concepção de que a educação da primeira infância deve ser compartilhada entre a família e o poder público. O texto da UNESCO (2002) diz o seguinte:

A grande maioria dos países (OCDE) reconhecem que os serviços destinados à primei-

\footnotetext{
${ }^{3}$ Estudo editado e lançado pela UNESCO durante as comemorações da "Semana Mundial da UNESCO de Educação para Todos" realizada de 22 a 26 de abril de 2002, considerado pela UNESCO o estudo mais abrangente no campo das políticas de educação e cuidado para a criança de zero a seis anos já realizado pela OCDE. Estabelece relações entre as atuais políticas desenvolvidas em 12 países membros - Austrália, Bélgica Comunidade Flamenga, Bélgica Comunidade Francesa, Dinamarca, Estados Unidos da América, Finlândia, Itália, Holanda, Noruega, Portugal, República Tcheca, Reino Unido e Suécia.
}

ra infância oferecem a possibilidade de identificar crianças com necessidades especiais ou em situação de risco; neste caso, tem a possibilidade de intervir o mais cedo possível a fim de prevenir ou reduzir as dificuldades ulteriores. (p.60).

Assim a educação e cuidado na primeira infância passam a ser vistos na maioria dos países da OCDE como complementares aos cuidados da família, e não como substitutos. A grande contribuição dos serviços de educação infantil é a de oferecer a possibilidade de apoio social e ponto de encontro entre família e sociedade. De acordo com este referencial, existe a concepção de que a educação na primeira infância deve preparar a criança para ser bem sucedida em sua escolaridade, vida profissional e em sociedade. Nos países em que esta visão é difundida, são destinadas verbas às famílias consideradas de risco com o objetivo de que as crianças sejam estimuladas a se tornarem autônomas e sejam diminuídos gastos com assistência social, delinqüência e outros problemas sociais.

A maioria dos países membros da OCDE considera assim que o acesso universal à educação e cuidado na primeira infância é um meio de promover igualdade de oportunidades educativas; e particularmente as crianças em situação "de risco", ou as que têm necessidades especiais, poderão se beneficiar de condições ótimas de aprendizagem quando ingressarem no ensino fundamental. Ressaltam ainda a importância de a educação infantil considerar a "criança em sua totalidade" e garantir o respeito às suas necessidades, uma vez que são muitas as oportunidades de aprendizagem em diferentes situações e contextos do cotidiano.

\section{Pobreza e educação infantil}

A modificação do quadro demográfico, econômico e social, ocorrida nos últimos anos nos países participantes do estudo da OCDE, contribui para a compreensão do contexto no qual se inserem as atuais políticas de educação e cuidado na primeira infância (UNESCO, 2002). Alguns exemplos das alterações dos contextos são: a constituição tardia da família, a formação de famílias monoparentais, o au- 
mento da participação da mulher no mercado de trabalho. Estes fatos trazem a necessidade de maior acesso das crianças a um serviço de atendimento à infância com qualidade. Além disso, a distribuição de emprego não é realizada de forma igualitária, verificando-se altas taxas de desemprego para as populações cujo nível de instrução é mais precário e o rápido crescimento da proporção de casais que não recebem nenhum tipo de salário, com dramáticas conseqüências econômicas e sociais para as crianças.

Em relação à situação da mãe que trabalha, o documento apresenta dados que mostram as conseqüências sobre as políticas de educação e cuidado na primeira infância: além do crescente número de mães de crianças muito jovens que trabalham, muitos empregos têm se caracterizado por serem sazonais, fora de normas trabalhistas, desempenhados em horários atípicos, com prolongamento da duração média da semana de trabalho. Todos estes fatores são considerados um desafio para a organização de serviços de atendimento à criança, na medida em que necessitam de adaptação a esta diversidade de modalidades de trabalho. Com exceção dos Estados Unidos e da Austrália, todos os países participantes do estudo mantêm políticas de licença maternidade e proteção do emprego à mãe que trabalha (embora com características de remuneração diferentes). A OCDE considera que tais políticas se constituem em importantes contribuições para a educação e o cuidado dos bebês e crianças mais novas, e ainda um meio de conciliarem responsabilidades profissionais e familiares.

Pesquisas demonstram efeitos a curto prazo da educação e cuidado na primeira infância sobre o desenvolvimento cognitivo e sócio-afetivo das crianças (Barnett, 1995; Boocok, 1995; Jarousse et al., 1992, apud UNESCO, 2002). Mas tais benefícios podem não ser suficientes quando a criança apresenta necessidades essenciais em relação à saúde, nutrição e moradia.

O relatório "Situação da Infância Brasileira 2001” (UNICEF, 2001) aponta que o maior desafio do país em relação ao desenvolvimento infantil consiste em apoiar as famílias para que estejam aptas a cuidar de suas crianças e garantir qualidade nos serviços públicos. O estudo mostra que, embora a rede de serviços de saúde, educação e assistência social seja satisfatória e tenham sido criados marcos importantes de atenção à criança (como o Estatuto da Criança e do Adolescente, as Leis Orgânicas de Saúde, a Lei de Diretrizes e Bases da Educação, os Programas de Saúde da Família), ainda há necessidade de melhora na qualidade do atendimento que é oferecido às crianças de zero a seis anos de idade. $\mathrm{E}$ afirma que esta depende do esforço conjunto de governos e sociedade.

O relatório brasileiro constata que, da mesma forma que nos países membros da OCDE, no Brasil ocorreu uma queda na taxa de fertilidade das mulheres e, pela primeira vez na história, o número de crianças de zero a seis anos de idade decresceu 3,4\%, ou seja, de 1991 a 1999 o número de crianças nessa faixa etária passou de 23,9 milhões para 23,1 milhões. E afirma que este é um excelente momento para investir em políticas de desenvolvimento infantil. (UNICEF, 2001, p. 23). O relatório descreve ainda os avanços na situação da infância brasileira, entre eles a queda do índice de mortalidade infantil (de 47,8 mortes para cada mil nascidos vivos em 1990 para 36,1 em 1998). Apesar desta queda, o país não atingiu a meta estabelecida de 31,9 por mil, e são alarmantes as disparidades das taxas de mortalidade em relação às diferentes regiões do país. A redução do índice de baixo peso ao nascimento também foi importante, sendo que a taxa de crianças nascidas com menos de 2500 gramas em 1989 era de 10\%, passando para 9,2\% em 1996. O número de crianças com retardo de crescimento também foi reduzido em um terço neste período, embora este índice não tenha atingido as áreas rurais, onde as crianças ainda apresentam déficits entre a altura e a idade. Mas, sem dúvida, uma grande conquista do Brasil nos últimos anos foi o aumento dos índices de imunização contra tétano, difteria, sarampo, coqueluche, tuberculose e poliomielite, mostrando que ótimos resultados podem ser obtidos quando a intervenção envolve a família, a comunidade e os serviços públicos.

Entretanto, o estudo da UNICEF (2001) alerta que muitos desafios ainda estão por ser superados para garantir os direitos das crianças. O maior deles é a pobreza. No Brasil, 30,5\% das famílias com crianças de zero a seis anos de idade vivem com renda per capita igual ou inferior a meio salário mínimo, sendo que na região Nordeste este índice aumenta 
para 53,6\%. O relatório declara que:

"pobreza significa mais do que renda insuficiente para cobrir as necessidades mínimas da família. Sinais de que as necessidades básicas não estão sendo atendidas - como saúde frágil, baixa escolaridade, discriminação e marginalização - também são indicadores de pobreza. Assim, a pobreza está ligada ao acesso inadequado a serviços básicos, como boas creches e suas alternativas, pré-escolas, postos de saúde e saneamento adequado" (UNICEF, 2001, p. 27).

Sabe-se que as crianças são as mais atingidas pela pobreza, que é causa de milhares de mortes, evasão escolar, fome e exploração. E como os outros indicadores brasileiros, a pobreza também é marcada por desigualdades que estão presentes em cada região do país.

Um outro grave problema ainda relacionado à garantia de direitos das crianças brasileiras é o alto índice de mortalidade materno-infantil. Vários fatores contribuem para esta situação, entre eles: a escolaridade da mãe (quanto menor o nível de escolaridade, maior o risco de mortalidade do filho), os partos de mães adolescentes (todos os anos são realizados mais de 730 mil partos de meninas entre 10 e 19 anos na rede pública de saúde), a qualidade dos serviços de acompanhamento pré-natal (na região Nordeste, 26 em cada 100 mães não realizam nenhuma consulta pré-natal), a alta quantidade de partos cesáreos (41\%, enquanto que a OMS recomenda o índice máximo de 15\%) e ainda, considerados mais graves, os elevados índices de morte de crianças com menos de um ano de idade por causas indefinidas e de morte materna por causas facilmente detectáveis, como hipertensão e infecções.

O relatório da UNICEF (2001) coloca que, "assim como muitos desafios ainda devem ser superados em relação à garantia de saúde das crianças, também é necessário avançar no sentido de assegurar o seu atendimento em creches e pré-escolas. O documento afirma que apenas 6,3 milhões dos 21 milhões de crianças de zero a seis anos freqüentam a educação infantil e que na faixa etária de zero a três anos, somente $8,3 \%$ estão matriculadas em creches e de quatro a seis anos apenas 57\% estão em préescolas. A oferta de educação infantil é um dever dos municípios, que podem destinar $10 \%$ dos $25 \%$ do orçamento para a educação infantil. O estudo conclui que principalmente para as crianças que provêm de famílias de baixa renda, o espaço da educação infantil representa a maior fonte de estímulos sociais e cognitivos, e por isso, é urgente estendê-lo para as mais novas, mais pobres e as que vêm de zonas rurais e periferias" (p. 38).

Dentre outros problemas que atingem as crianças brasileiras, o relatório aponta os maus tratos, o trabalho infantil, o abuso, a violência e a privação do convívio familiar, todos com enorme impacto na vida da criança. $\mathrm{O}$ estudo recomenda a necessidade urgente de transmissão de informações a profissionais da saúde e da educação a fim de que comuniquem os casos às autoridades competentes.

\section{E quais são as discussões que permeiam o tema “cuidado e educação" no contexto das instituições brasileiras?}

Kuhlmann Jr. (2000), em seu parecer sobre o Referencial Curricular Nacional da Educação Infantil, aborda a questão da função da educação infantil, relatando que no Brasil, a polarização entre assistência e educação tem sido contemplada do ponto de vista teórico, entretanto permanece intocada a realidade institucional nas questões que efetivamente discriminam a população pobre.

O autor, em suas considerações traz a relação entre a oferta de determinadas ações educativas e de cuidado com a situação social e econômicas das famílias. Afirma que, várias pesquisas têm mostrado que tanto a creche como a pré-escola constituíramse historicamente como instituições educacionais, e o que as diferencia é o público e a faixa etária atendida. Como estas instituições são destinadas à infância pobre, o assistencialismo tem se tornado a própria proposta pedagógica:

"O fato dessas instituições carregarem em suas estruturas a destinação a uma parcela social, a pobreza, já representa uma concepção educacional. A pedagogia das instituições educacionais para os pobres é uma pedago- 
gia da submissão, uma educação assistencialista marcada pela arrogância que humilha para depois oferecer o atendimento como uma dádiva, como um favor para os poucos selecionados para o receber". (Kuhlmann Jr.,2000, p. 54).

Foi um passo importante a vinculação das creches e pré-escolas ao sistema educacional, mas de acordo com a realidade nacional, são ainda observadas desigualdades quanto à distinção das faixas etárias atendidas e à denominação dessas instituições (por exemplo, alguns locais denominam "creche" o atendimento de zero a seis anos). Além disso, Kuhlmann Jr. (2000) aponta um cuidado que deve ser levado em consideração a despeito desse "avanço": nos Referenciais Curriculares Nacionais da Educação Infantil (versão preliminar - Brasil, 1997) as propostas para a educação das crianças de zero a seis anos "subordinam-se ao que é pensado para as maiores, seguindo um atrelamento ao ensino fundamental" (p.56). As tendências mais recentes das pesquisas sobre a educação infantil enfatizam a necessidade de ser considerado o processo social, cultural e histórico da criança de zero a seis anos, e não sistematizar seu conteúdo para enquadrá-lo nos moldes do ensino fundamental.

O autor aponta a adoção, recente, da expressão inglesa - "educare" - que atribui à educação infantil o papel de educar e cuidar, com o objetivo, portanto, de tornar o trabalho pedagógico conseqüente com a criança pequena. Esta afirmação vai ao encontro do relatório preparado pelos países membros da OCDE (UNESCO, 2002), que mostrou a forte indicação de integrar o cuidado com a educação das crianças de zero a seis anos de idade.

\section{Considerações finais}

O presente estudo teve por objetivo realizar uma reflexão acerca dos aspectos envolvidos na melhoria de qualidade de vida de algumas crianças e suas famílias nos primeiros anos de vida. Na atualidade, fica evidenciada a presença de inúmeros fatores que contribuem ou dificultam a promoção do desenvolvimento. Um agrupamento das variáveis envolvidas permite observar a presença de diferen- tes setores, como o da saúde, educação, meio ambiente, dentre outros.

Uma visão intersetorial, ao nosso ver, poderá se constituir em um caminho, quando se objetiva a promoção da saúde e educação de crianças pequenas no Brasil. Saúde, ambiente e desenvolvimento são conceitos que não podem caminhar sozinhos, considerando inúmeros estressores e situações de risco aos quais as famílias e parcelas/camadas mais desfavorecidas estão expostas na atualidade. Para Guralnick (1997) fator de risco é “... qualquer fator que interfira na habilidade da família em interagir com a criança de modo a assegurar seu desenvolvimento" (p. 03). Sendo assim, o suporte às famílias pode assegurar o pleno desenvolvimento de crianças pequenas.

De acordo com o relatório da UNICEF (2001), algumas iniciativas bem sucedidas vêm assegurando a promoção do desenvolvimento da criança nos primeiros anos de vida, como "garantir a formação adequada de todos os agentes de desenvolvimento infantil - profissionais de saúde, de educação e de serviço social". Além disso, recomenda que "as famílias e comunidades precisam ter acesso a informações sobre desenvolvimento infantil” ( p. 44).

Esse acesso à informação, ao nosso ver, é fundamental tanto para profissionais como para familiares, pois na medida em que são informadas, as pessoas compreendem etapas do desenvolvimento infantil, associam com ações de sua prática (familiar ou educacional) e identificam fatores de risco. Passam a se constituir em efetivos "triadores", com base no suporte informativo, o qual fornece a estrutura para o desenvolvimento do empowerment, ou "empoderamento". As possibilidades do empowerment oferecem condições para que famílias e educadores possam assumir os cuidados com a criança diante de um contexto maior, a sociedade (Thompson, 1997).

A vertente educacional mostra-se como um caminho importante para efetivação da melhoria da qualidade de vida da população bem como para a promoção à saúde, especialmente o investimento da formação do educador tendo como um dos pilares a compreensão de que a valorização da auto-estima e autonomia são fundamentais para o desenvolvimento e promoção a saúde. 


\section{Referências Bibliográficas}

Brasil, Ministério da Educação e do Desporto. Secretaria da Educação Fundamental (1997). Referenciais Curriculares Nacionais para a Educação Infantil. Documento introdutório (pp.1-82). Versão preliminar. Brasília: MEC/ SEF/DPE/COEDI.

Guralnick, M.J. (1997). Second-generation research in the field of early intervention. Em M.J. Guralnick (Org.), The effectiveness of early intervention (pp. 3-20). Baltimore: Paul Brookes Publishing, Co.

Kuhlmann Jr., M. (2000). Educação infantil e currículo. Em A. L. de Faria \& M.S. Palhares (Orgs.), Educação infantil Pós-LDB: rumos e desafios. (pp. 51-65) Campinas: Autores Associados FE/UNICAMP; São Carlos: Editora da UFSCar; Florianópolis: Editora da UFSC.

Thompson, L. (1997). Pathways to family empowerment: effects of family-centereddelivery of early intervention services. Exceptional Children, 64, 99-113.

UNESCO, Educação e cuidado na primeira infância: grandes desafios. Tradução de G. J. F. Teixeira. Brasília: UNESCO Brasil, OECD, Ministério da Saúde.

UNICEF, (2001). Situação da Infância Brasileira 2001. UNICEF Brasil, Brasília. 